\title{
Rituximab for treatment of severe lupus nephritis
} E Baskin*1, US Bayrakci ${ }^{1}$, S Ozen ${ }^{2}$, Y Bilginer ${ }^{2}$, KS Gulleroglu ${ }^{1}$ and H Ozdemir ${ }^{1}$

Address: ${ }^{1}$ Baskent University Department of Pediatric rheumatology and nephrology, Ankara, Turkey and ${ }^{2}$ Hacettepe University Department of Pediatric rheumatology and nephrology, Ankara, Turkey

* Corresponding author

from $15^{\text {th }}$ Paediatric Rheumatology European Society (PreS) Congress

London, UK. 14-17 September 2008

Published: 15 September 2008

Pediatric Rheumatology 2008, 6(Suppl I):P249 doi:10.1 186/1546-0096-6-SI-P249

This abstract is available from: http://www.ped-rheum.com/content/6/SI/P249

C 2008 Baskin et al; licensee BioMed Central Ltd.

\section{Background}

Systemic lupus erythematosus (SLE) is a challenging disease to diagnose and manage. Treatment of lupus nephritis in resistant cases is still a matter of debate.

\section{Aim}

To investigate the effectiveness of rituximab (Rx) in treatment resistant cases of lupus nephritis.

\section{Materials and methods}

Five female patients with a median age of 14 years (range: 12-16 years) with class IV (3/5) and class II (2/5) lupus nephritis were treated with rituximab, steroids and plasmapheresis. Rituximab was given with a dose of $375 \mathrm{mg} /$ $\mathrm{m} 2$ /week for 4 weeks. Two patients had severe thrombocytopenia, while one of them had developed macrophage activating syndrome. All of them had renal failure with high serum creatinine. ANA and anti ds DNA levels were found to be high in 4 patients with low levels of compleman 3.

\section{Results}

Thrombocytopenia was completely resolved at the end of 4 weeks in both patients while only one patient had complete remission of the SLE. Partial remission was observed in two patients and 2 patients did not respond at all.

\section{Conclusion}

Rituximab could be effective in treatment of patients with severe, treatment resistant lupus nephritis. 